\title{
Tracking the train of thought from the laboratory into everyday life: An experience-sampling study of mind wandering across controlled and ecological contexts
}

\author{
Jennifer C. McVay, Michael J. Kane, ANd Thomas R. KwapiL \\ University of North Carolina, Greensboro, North Carolina
}

\begin{abstract}
In an experience-sampling study that bridged laboratory, ecological, and individual-differences approaches to mind-wandering research, 72 subjects completed an executive-control task with periodic thought probes (reported by McVay \& Kane, 2009) and then carried PDAs for a week that signaled them eight times daily to report immediately whether their thoughts were off task. Subjects who reported more mind wandering during the laboratory task endorsed more mind-wandering experiences during everyday life (and were more likely to report worries as off-task thought content). We also conceptually replicated laboratory findings that mind wandering predicts task performance: Subjects rated their daily-life performance to be impaired when they reported off-task thoughts, with greatest impairment when subjects' mind wandering lacked metaconsciousness. The propensity to mind wander appears to be a stable cognitive characteristic and seems to predict performance difficulties in daily life, just as it does in the laboratory.
\end{abstract}

The study of mind wandering provides a novel means to explore fundamental issues of consciousness. For example, the commonplace experience of moving one's eyes across a page without comprehending a thing suggests the startling conclusion that we are sometimes unaware of our own conscious experience; if we "knew" our thoughts were elsewhere, we would return to reading or drop the charade (Schooler, Reichle, \& Halpern, 2004). Moreover, despite controversy about the causal functions of consciousness (e.g., Morsella, 2005; Rosenthal, 2008; Wegner, 2002), field and laboratory studies of human performance (e.g., Reason, 1990; Smallwood et al., 2004) indicate that errors increase when people report experiencing task-unrelated thoughts (TUTs). Mind wandering thus co-occurs with events of scientific and practical interest. It is also beginning to figure into general theories of executive control, metacognition, and the "default mode" brain network (e.g., Bar, 2007; Buckner \& Carroll, 2007; Burgess, Dumontheil, \& Gilbert, 2007; Mason et al., 2007; Schooler, 2002; Smallwood \& Schooler, 2006); we have argued, for example, that unwanted mind-wandering experiences represent momentary failures of goal maintenance that reflect, in part, enduring individual differences in executive control (Kane et al., 2007; McVay \& Kane, 2009).

Like most areas of cognitive investigation, mindwandering research is dominated by laboratory and neuroimaging methods; here, subjects engage in an ongoing task that is periodically interrupted for them to report or cat- egorize their current thoughts (e.g., as on or off task; Giambra, 1995; Mason et al., 2007; Smallwood, McSpadden, \& Schooler, 2007). Such thought-probe responses appear to be valid: TUT reports vary systematically with experimental manipulations, such as memory load, stimulus pacing, and task practice (e.g., Antrobus, Singer, \& Greenberg, 1966; Teasdale, Proctor, Lloyd, \& Baddeley, 1993); TUTs show a reliable neural signature (e.g., Mason et al., 2007); and task errors can increase by $25 \%$ during TUTs as opposed to on-task thoughts (McVay \& Kane, 2009; Schooler et al., 2004). As well, individual differences in TUT rates are reliable across different primary tasks and across substantial test-retest lags (Giambra, 1995; Grodsky \& Giambra, 1990/1991) and they are predicted by objective cognitive ability assessments (McVay \& Kane, 2009).

Unlike some heavily investigated cognitive phenomena, however, mind wandering seems ubiquitous in everyday life. Perhaps for this reason, researchers have also investigated TUTs in ecologically valid contexts, by inserting thought probes into normal classroom activities (e.g., Cameron \& Giuntoli, 1972; Geerligs, 1995) or by electronically paging ("beeping") subjects to answer questions about their thoughts, emotions, and environmental context during unconstrained daily activities (e.g., Hurlburt, 1979). As in laboratory studies, daily-life mind wandering occurs frequently and it varies reliably with context: Subjects report TUTs on $30 \%-40 \%$ of probes, overall (e.g., Klinger \& Cox, 1987/1988), but they occur more often

M. J. Kane, mjkane@uncg.edu 
Table 1

Mean Ratings (1-7) for Perceived Thought Control and Content When Subjects Reported Daily-Life Mind Wandering

\begin{tabular}{lc}
\hline \multicolumn{1}{c}{ Questionnaire Prompt } & $M \pm S D$ \\
\hline I was aware my mind was wandering in the moments before the beep. & $4.40 \pm 0.95$ \\
I allowed my thoughts to wander on purpose. & $4.06 \pm 0.96$ \\
I was thinking about personal concerns or things I need to do. & $4.29 \pm 1.00$ \\
I was daydreaming or fantasizing about something. & $3.81 \pm 1.25$ \\
I was worrying about something. & $3.37 \pm 1.05$ \\
\hline
\end{tabular}

during classroom lectures than during discussions (e.g., Schoen, 1970), and less often during enjoyable activities and happy moods (e.g., Kane et al., 2007).

The goal of the present work was to bridge the controlled and ecological approaches to mind-wandering research by asking whether people who experience more (or fewer) TUTs during a challenging laboratory task also experience more (or fewer) TUTs in daily life. If mind wandering reflects, in part, executive-control failure (Kane et al., 2007; McVay \& Kane, 2009) and if executive-control capabilities are domain general (e.g., Engle \& Kane, 2004), then subjects' TUT rates in the lab should predict those outside the lab. To test this prediction, we administered a daily-life experience-sampling protocol to subjects who had previously completed a laboratory assessment of mind wandering during an executive-control, go/no-go task, the sustained attention to response task (SART; Robertson, Manly, Andrade, Baddeley, \& Yiend, 1997; Smallwood et al., 2004). McVay and Kane reported that these subjects experienced frequent mind wandering, high error rates, quite variable response times to "go" trials, and significant associations among the three.

Our secondary goal was to examine the relation between mind wandering and performance in daily life, a relation that is well established in the laboratory (e.g., McVay \& Kane, 2009; Schooler et al., 2004; Smallwood, McSpadden, \& Schooler, 2007). We therefore asked subjects to evaluate their performance of ongoing activities on the same occasions on which we probed their thoughts. We expected that in life, as in the lab, subjects would report performing less well when mind wandering than during on-task thinking.

\section{METHOD}

\section{Laboratory SART}

The SART presented 1,810 words for go/no-go responses based on a perceptual (letter case) or semantic (animals vs. foods) discrimination. Subjects pressed a key for nontarget "go" stimuli (e.g., lowercase words) and withheld responses to infrequent (11\%) target "no-go" stimuli (e.g., uppercase words; for details, see McVay \& Kane, 2009).

Thought-probe screens followed $60 \%$ of the no-go targets and presented the question, "What were you just thinking about?" with the following response options: (1) the task; (2) own task performance; (3) everyday stuff; (4) current state of being; (5) personal worries; (6) daydreams; and (7) other. We instructed subjects to report what they had been thinking immediately before the probe, and the experimenter initially elaborated on the response option meanings. For all analyses, Options 3-7 were considered TUTs.

Table 2

Contextual Predictors of Daily-Life Mind-Wandering Episodes

\begin{tabular}{lrrrr}
\hline & $b \pm S E$ & $t(71)$ & $p$ & $p_{\text {rep }}$ \\
\hline Negative & & & & \\
I was doing this activity successfully. & $-.541 \pm .049$ & -10.949 & .000 & .99 \\
I was trying to concentrate on what I was doing. & $-.577 \pm .057$ & -10.135 & .000 & .99 \\
I like what I'm doing right now. & $-.177 \pm .024$ & -7.421 & .000 & .99 \\
I am trying hard at what I'm doing right now. & $-.155 \pm .029$ & -5.366 & .000 & .99 \\
I feel happy right now. & $-.145 \pm .033$ & -4.358 & .000 & .99 \\
I'm good at what I'm doing right now. & $-.124 \pm .030$ & -4.132 & .000 & .99 \\
What I'm doing right now is important. & $-.083 \pm .021$ & -3.163 & .003 & .98 \\
It takes a lot of mental effort to do this activity. & $-.077 \pm .027$ & -2.912 & .005 & .98 \\
Positive & & & & \\
I would prefer to do something else right now. & $.168 \pm .022$ & 7.507 & .000 & .99 \\
What I'm doing right now is boring. & $.173 \pm .026$ & 6.555 & .000 & .99 \\
There is a lot going on around me right now. & $.063 \pm .026$ & 2.451 & .017 & .95 \\
I feel anxious right now. & $.084 \pm .032$ & 2.259 & .027 & .94 \\
I feel tired right now. & $.073 \pm .032$ & 2.259 & .027 & .94 \\
What I'm doing right now is stressful. & $.050 \pm .024$ & 2.092 & .040 & .93 \\
Nonsignificant & & & & \\
What I'm doing now is mentally challenging. & $-.043 \pm .027$ & -1.625 & .108 & .87 \\
What I'm doing now is related to schoolwork. & $.029 \pm .019$ & 1.483 & .142 & .85 \\
What I'm doing right now is unusual for me. & $-.007 \pm .027$ & -0.276 & .783 & .63 \\
I'm interacting with other people right now. & $-.002 \pm .019$ & -0.123 & .903 & .54 \\
\hline
\end{tabular}

Note-Parallel analyses from Kane et al. (2007) considered the contextual predictors of on-task thinking, and so the signs of the $b$ and $t$ values here are reversed in comparison with that study. 


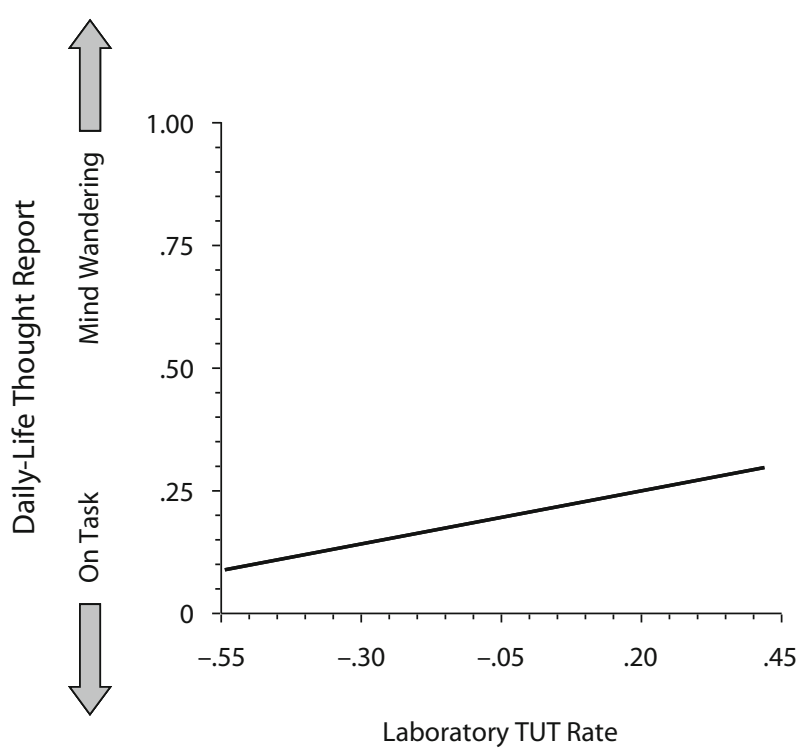

Figure 1. The relation between daily-life mind wandering and the propensity to experience task-unrelated thoughts (TUTs) during a lab task. Values on the $y$-axis represent the mind-wandering dependent variable, scored on each questionnaire as either 1 (for mind wandering) or 0 (for on-task thoughts). Values on the $x$-axis represent the grand-mean centered laboratory TUT rate.

\section{Subjects}

Of 244 undergraduates (aged 18-35) who completed the laboratory SART, 72 subsequently completed the experience-sampling study (ESM). Subjects began the 7-day ESM collection period between 1 and 63 days $(M=16 ; S D=13)$ after the laboratory session, on the basis of their availability. This subsample had laboratory TUT rates similar to the full sample's (both $M \mathrm{~s}=.55$ ) and similar levels of SART performance $\left[M\right.$ signal detection accuracy $\left(d_{\mathrm{L}}\right)=3.73$ vs. 3.35, respectively; mean go-trial response time (RT) variability $\left(\mathrm{RT}_{S D}\right)=151 \mathrm{msec}$ vs. $158 \mathrm{msec}$, respectively]; for analyses of the full sample, see McVay and Kane (2009). ${ }^{1}$

\section{Experience-Sampling Protocol}

Palm Pilot PDAs using iESP software (Barrett \& Barrett, 2004; Intel Corp., 2004) presented questionnaires and collected data during subjects' daily-life activities. A "beep" signaled subjects to complete eight daily questionnaires, between noon and midnight, for 7 full days. The signals occurred once randomly during each 90 -min block. During a 60-min training session, the experimenter instructed subjects to take immediate stock of their thoughts upon the beep and to report on only these thoughts; the experimenter also familiarized subjects with the PDAs, questionnaires, and mind-wandering examples. PDA signal blocks began immediately after subjects left the session (yielding an additional, partial day of data collection). Subjects completing $\geq 70 \%$ of the questionnaires were entered into a lottery for a retailer gift card.

The PDA questionnaire first asked subjects whether their current thoughts had wandered from their activity $(1=y e s ; 0=n o)$. If so, they answered 5 questions about those thoughts; all subjects also answered 18 questions about their mental and environmental context (all on a 1-7 scale; see Tables 1 and 2).

\section{Statistical Analyses}

Experience-sampling data have a hierarchical structure in which responses (Level 1 data) are nested within subjects (Level 2 data) and are best analyzed with multilevel or hierarchical linear modeling (HLM; Raudenbush \& Bryk, 2002). We used HLM to examine within- and between-subjects predictors of two daily-life outcomes: mind wandering and subjective evaluation of activity performance. All Level 1, within-subjects variables (e.g., self-reported happiness) were standardized within subjects (group centered). The mindwandering variable was dichotomous (on task vs. TUT), which violates the normality assumption of HLM; we therefore used an HLM model for binary outcomes (using a log transformation and Bernoulli sampling distribution, a special case of the binomial distribution where the values are 0 and 1 ; see Raudenbush \& Bryk, 2002) to evaluate Level 1 and Level 2 effects on TUTs. We analyzed three Level 2 between-subject predictors of thought and performance (grand-mean centered): SART session TUT rate, $d_{\mathrm{L}}$, and $\mathrm{RT}_{S D}$.

\section{RESULTS}

We report nondirectional NHSTs $(\alpha=.05)$ with $p_{\text {rep }}$ values. On average, subjects completed $45.6(S D=$ 10.8 , range $=20-65$ ) usable questionnaires, which were uncorrelated with daily-life $[r(72)=-.04]$ and laboratory $[r(72)=-.13]$ TUT rates.

\section{Mind Wandering in Daily Life}

Our initial analyses examined the frequency and nature of daily-life mind wandering. Consistent with previous findings, subjects reported TUTs at $30 \%$ of the beeps, on average, with considerable variation among subjects $(S D$, $15 \%$; range, $6 \%-75 \%$ ). Table 1 presents mean ratings of thought content and awareness when subjects reported mind wandering; replicating Kane et al. (2007), subjects generally reported more personal-concern content than fantasy, and more fantasy than worry (but these categories were not mutually exclusive, because concern-related content might intrude into worries or daydreams; see Klinger,

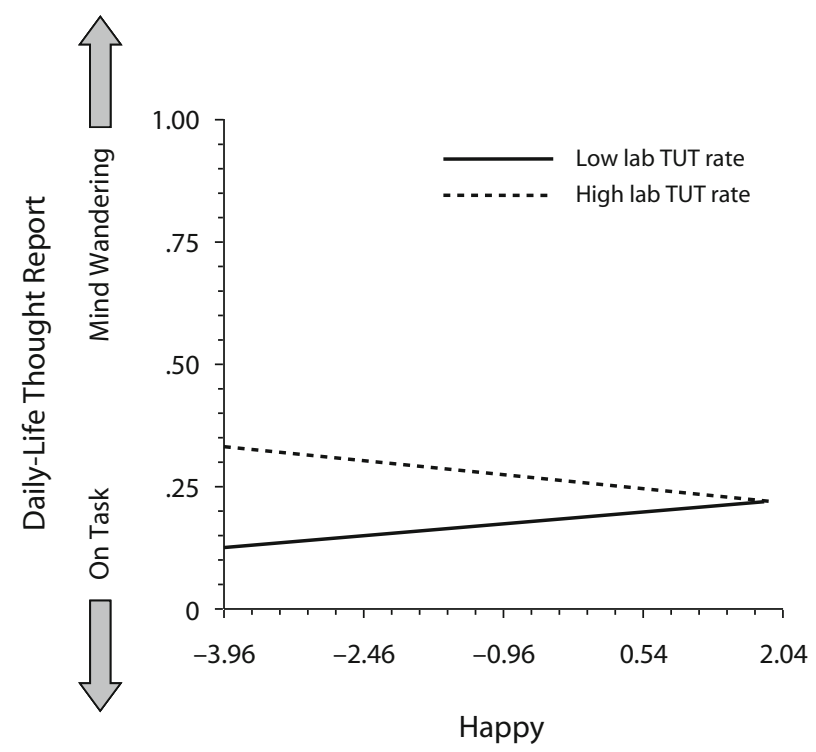

Figure 2. The relation between daily-life mind wandering and self-reported happiness as a function of the propensity to experience task-unrelated thoughts (TUTs) during a lab task. Lines depict the means of the within-person slopes for subjects in the top and bottom quartiles for laboratory TUT rate. Values on the $y$-axis represent the mind-wandering dependent variable, scored on each questionnaire as either a 1 (for mind wandering) or 0 (for on-task thoughts). Values on the $x$-axis represent group-centered ratings for happiness ("I feel happy right now"). 
Table 3

Significant Contextual Predictors of Daily-Life Performance Ratings

\begin{tabular}{lcrcr}
\hline & $b \pm S E$ & $t(71)$ & $p$ & $p_{\text {rep }}$ \\
\hline Positive & & & & \\
$\quad$ Trying to concentrate & $.349 \pm .025$ & 14.024 & .000 & .99 \\
Like activity & $.206 \pm .018$ & 11.493 & .000 & .99 \\
Good at activity & $.243 \pm .025$ & 9.595 & .000 & .99 \\
Important activity & $.126 \pm .017$ & 7.283 & .000 & .99 \\
Feeling happy & $.192 \pm .026$ & 7.368 & .000 & .99 \\
Trying hard & $.129 \pm .022$ & 5.957 & .000 & .99 \\
Negative & & & & \\
Prefer something else & $-.115 \pm .019$ & -6.452 & .000 & .99 \\
Boring activity & $-.131 \pm .020$ & -6.436 & .000 & .99 \\
Stressful activity & $-.099 \pm .023$ & -4.391 & .000 & .99 \\
A lot going on around me & $-.053 \pm .018$ & -2.905 & .005 & .98 \\
Feeling tired & $-.038 \pm .014$ & -2.647 & .010 & .97 \\
Feeling anxious & $-.048 \pm .022$ & -2.201 & .031 & .94 \\
\hline
\end{tabular}

1971). Also replicating the findings from Kane et al. (2007), mind wandering varied significantly with context (Table 2), increasing with stress, boredom, sleepiness, or chaotic environments, and decreasing with concentration, effort, successful performance, enjoyable tasks, or happiness. However, in contrast to Kane et al., TUTs decreased during more important and more effortful activities and did not increase during schoolwork. ${ }^{2}$ In general, these findings are congruent with Klinger's "current concerns" theory, which argues that thoughts about one's current goals will be especially likely to intrude into consciousness when they are cued by the environment, particularly during less important or less goal-relevant tasks (Klinger, 1971, 1999; see Kane et al., 2007, for further discussion of contextual predictors of mind wandering).

For our primary question - about the stability of off-task thinking - we evaluated the effects of our three laboratory variables on daily-life mind wandering using a model that included the significant Level 1 context variables from Table 2. As hypothesized, subjects with higher laboratory TUT rates also reported more daily-life TUTs $(b=1.29$, $S E=0.61)\left[t(68)=2.12, p_{\text {rep }}=.93\right]$ (see Figure 1). Note also that happiness moderated this effect (see Figure 2), such that when subjects were happier than usual it minimized the mind-wandering differences between subjects with high versus low laboratory TUT rates $(b=-0.65$, $S E=0.20)\left[t(68)=-3.26, p_{\text {rep }}=.99\right]$. Neither SART accuracy $\left(d_{\mathrm{L}}\right)$ nor RT variability $\left(\mathrm{RT}_{S D}\right)$ significantly predicted daily-life TUTs [both $t \mathrm{~s}(68)<1.85$ ].

In a more exploratory vein, we examined whether laboratory TUT rate predicted daily-life mind-wandering content. In fact, it predicted worrying (see Figure 3): When subjects' daily-life thoughts were off task, those who had experienced more lab TUTs reported more worried content than did those who had experienced fewer lab TUTs $(b=1.49, S E=0.53)\left[t(68)=2.84, p_{\text {rep }}=.97\right]$. Lab TUT rate did not predict any other mind-wandering qualities.

\section{Performance in Daily-Life Activities}

Before we address the critical question of whether daily-life thoughts predicted performance, we point out that contextual factors predicted subjects' self-reported success at daily-life tasks, as shown in Table 3. Subjects reported performing better when engaged in important or enjoyable activities, when concentrating or expending effort, or when happy. They reported performing worse when engaged in stressful, unappealing, or boring activities, when in chaotic environments, or when anxious or tired.

Of central importance, and as predicted, subjects' performance ratings were lower while mind wandering than while mentally on task $(b=-1.15, S E=.10)[t(71)=$ $-11.69, p_{\text {rep }}>$.99]. We also found that mind-wandering awareness and content predicted perceived performance. When subjects were aware that they had been mind wandering, they believed they had been performing better than when they had been mind wandering without awareness $(b=.094, S E=.040)\left[t(71)=2.34, p_{\text {rep }}=.95\right]$. This finding mirrors laboratory reports of increased task errors during mind-wandering episodes that lack "metaconsciousness" (Smallwood, McSpadden, \& Schooler, 2007, 2008). Finally, with respect to mind-wandering content, when subjects experienced daily-life TUTs, their self-reported performance was worse with more worry- or fantasy-based content [for worry, $b=-.072, S E=.027$, $t(71)=-2.67, p_{\text {rep }}=.97$; for fantasy, $b=-.105, S E=$ $.026, t(71)=-4.02, p_{\text {rep }}>.99$ ]; neither purposeful mind wandering nor variation in personal-concern content predicted performance ratings ( $t \mathrm{~s}<1.28, p \mathrm{~s}>.21$ ).

\section{DISCUSSION}

We found that the propensity to mind wander is a stable cognitive characteristic, representing an individual difference that is reliable across time, activities, and con-

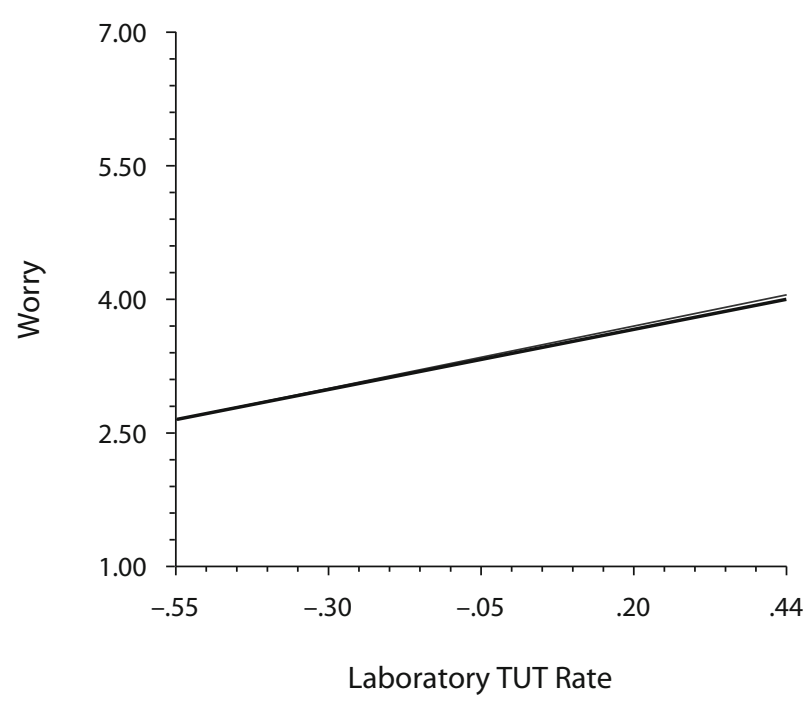

Figure 3. The relation between daily-life worry and the propensity to experience task-unrelated thoughts (TUTs) during a lab task. Values on the $y$-axis represent ratings for worry content (only completed on occasions on which subjects reported mind wandering), scored on each questionnaire on a 1-7 scale (higher values indicate more worrying). Values on the $x$-axis represent the grand-mean centered laboratory TUT rate. 


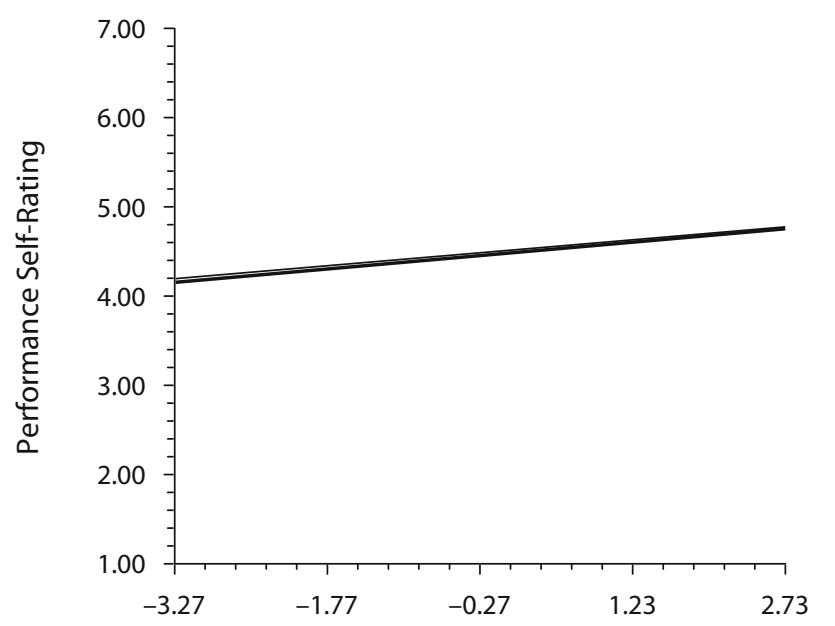

Mind-Wandering Awareness

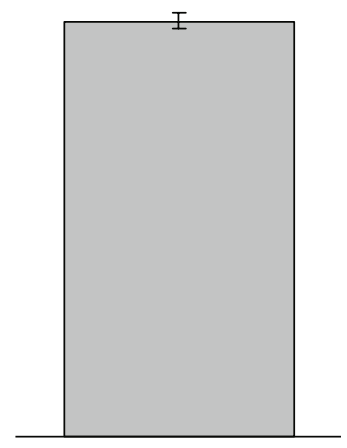

On-Task Thought

Figure 4. The relation between daily-life performance and thought. Values on the $y$-axis represent ratings for success in performing one's ongoing activity, scored on each questionnaire on a 1-7 scale (higher values indicate better performance). The line graph depicts the relation between performance and subjects' awareness that they had been mind wandering; values on the $x$-axis represent group-centered ratings for awareness ("I was aware my mind was wandering in the moments before the beep"). The bar graph depicts the mean performance rating on occasions when subjects reported on-task thoughts.

texts. Subjects with higher TUT rates during a laboratory executive-control task experienced more off-task thoughts during their unconstrained everyday activities. This relation held even though we measured daily-life TUTs several weeks after the initial lab assessment. Our TUT rate findings also differed in an important way from our previous results regarding laboratory measures of working memory capacity (WMC), which are correlated with, but not isomorphic to, laboratory TUT rates (McVay $\&$ Kane, 2009): Whereas WMC variation predicted dailylife mind-wandering differences only in cognitively demanding contexts (such as those perceived as requiring concentration; Kane et al., 2007), laboratory TUT rate variation predicted daily-life mind wandering across virtually all contexts. Thus, whatever variables, aside from WMC, contribute to high levels of mind wandering during laboratory tasks (e.g., personality, emotion, psychopathology, goals, recent life events), they assert their influence very broadly across people's everyday lives and activities.

Unexpectedly, we found that mood moderated the labto-life TUT relationship, with happiness being an equalizer. When people reported being especially happy in the moment, their laboratory TUT rate no longer predicted well whether they were currently mind wandering. We will not make too much of this unanticipated result. However, given that unhappiness exacerbated mind-wandering differences between lab TUTers and lab non-TUTers, and that lab TUTers were especially likely to be worrying when they did mind wander in daily life, future mind-wandering research should draw upon allied work in the clinical and personality domains, on phenomena such as rumination and worry and their covariation with depression and anxi- ety (e.g., Nolen-Hoeksema, Wisco, \& Lyubomirsky, 2008; Sarason, Pierce, \& Sarason, 1996; Smallwood, Fitzgerald, Miles, \& Phillips, 2009; Smallwood, O'Connor, Sudbery, \& Obonsawin, 2007; Watkins, 2008).

Our study conceptually replicated, in daily life, the common laboratory finding that task performance suffers on occasions when people report off-task versus on-task thought (e.g., McVay \& Kane, 2009; Schooler et al., 2004; Smallwood, Baracaia, Lowe, \& Obonsawin, 2003; Smallwood et al., 2004; Smallwood, McSpadden, \& Schooler, 2007, 2008; Smallwood, Riby, Heim, \& Davies, 2006). That is, subjects rated their ongoing activity performance to be worse when they were mind wandering than when they were mentally focused. Were these subjective reports valid? We believe so, although we could not measure subjects' performance objectively outside the laboratory. We see evidence for validity in that subjects' performance ratings varied systematically with contextual variables, metaconsciousness, and thought content, despite it being unlikely that subjects shared folk beliefs about the effects of metaconsciousness on performance, or about the effects of fantasy versus personal-concern thought content on performance. If we are right that the thought-performance relation is real, then the consistency with which our study and others find that $30 \%-40 \%$ of daily-life thoughts are off task (Hurlburt, 1979; Kane et al., 2007; Klinger, 1978/1979; Klinger \& Cox, 1987/1988) suggests a need to take mind wandering seriously as an impediment to learning, productivity, and public safety (e.g., Reason, 1990; Smallwood, McSpadden, \& Schooler, 2007; Wiegmann et al., 2005). ${ }^{3}$

As far as we know, our study is the first to demonstrate a relation between metaconsciousness and human perfor- 
mance outside the laboratory: Subjects performed their daily-life activities more poorly when they had been less aware, before the beep, of their TUTs. Our findings thus support the Smallwood and Schooler (2006; Smallwood, McSpadden, \& Schooler, 2007) argument that mind wandering without meta-awareness of one's mind wandering (or, "zoning out") is particularly harmful to task performance. At the same time, our data, like theirs, suggest that mind wandering with awareness can have negative consequences. Figure 4 shows that, whereas increased awareness of mind wandering was associated with higher self-rated performance, even the highest levels of meta-awareness during mind wandering predicted considerably lower performance ratings than did on-task thoughts; thus, awareness of off-task thought does not necessarily trigger enough (or timely enough) conscious focus to prevent errors. Further laboratory and daily-life research should address the performance consequences of mind wandering with and without awareness (see also Smallwood, Fishman, \& Schooler, 2007; Smallwood, McSpadden, \& Schooler, 2008).

Indeed, we suggest that mind wandering, in general, should become a phenomenon of choice in studies of conscious awareness, metacognition, executive control, and individual differences therein (see Smallwood \& Schooler, 2006). Unlike other theoretically diagnostic outcome variables, such as action slips, RT variability, and perseverative errors, mind wandering is readily observable (albeit indirectly) in a wide variety of laboratory tasks and ecological settings. Moreover, technological advances are increasingly allowing researchers to triangulate self-report, behavioral, and neuroimaging data as a means to better measure and understand mind wandering and other subjective experiences (e.g., Christoff, Gordon, Smallwood, Smith, \& Schooler, 2009; Mason et al., 2007; Smallwood, Beach, Schooler, \& Handy, 2008). We contend that ecological and individual-differences investigations of mind wandering, like the present one (see also Kane et al., 2007), should similarly contribute to building comprehensive theories of conscious awareness and control.

\section{AUTHOR NOTE}

We thank Nina Powell and Amethyst Royal for data collection assistance. Portions of this work were supported by a UNCG Regular Faculty Grant awarded to M.J.K. and an NIH Ruth L. Kirschstein National Research Service Award Individual Predoctoral Fellowship granted to J.C.M., Award F31MH081344 from the National Institute of Mental Health. The content is solely the responsibility of the authors and does not necessarily represent the official views of the NIMH. Correspondence concerning this article may be sent to M. J. Kane, Psychology Department, University of North Carolina, P.O. Box 26170, Greensboro, NC 27402-6170 (e-mail: mjkane@uncg.edu).

\section{REFERENCES}

Antrobus, J. S., Singer, J. L., \& Greenberg, S. (1966). Studies in the stream of consciousness: Experimental enhancement and suppression of spontaneous cognitive processes. Perceptual \& Motor Skills, 23, 399-417.

BAR, M. (2007). The proactive brain: Using analogies and associations to generate predictions. Trends in Cognitive Sciences, 11, 280-289.

Barrett, L. F., \& Barrett, D. J. (2004). The Experience Sampling Program (Version 2.0) [Computer software]. Retrieved February 2004 from http://www2.bc.edu/_barretli/esp/.
Buckner, R. L., \& CARroll, D. C. (2007). Self-projection and the brain. Trends in Cognitive Sciences, 11, 49-57.

Burgess, P. W., Dumontheil, I., \& GilberT, S. J. (2007). The gateway hypothesis of rostral prefrontal cortex (area 10) function. Trends in Cognitive Sciences, 11, 290-298.

Cameron, P., \& Giuntoli, D. (1972). Consciousness sampling in the college classroom or Is anybody listening? Intellect, 101, 63-64.

Christoff, K., Gordon, A. M., Smallwood, J., Smith, R., \& Schooler, J. W. (2009). Experience sampling during fMRI reveals default network and executive system contributions to mind wandering. Proceedings of the National Academy of Sciences, 106, 87198724.

Engle, R. W., \& Kane, M. J. (2004). Executive attention, working memory capacity, and a two-factor theory of cognitive control. In B. Ross (Ed.), The psychology of learning and motivation (pp. 145199). New York: Academic Press.

GeERLIGS, T. (1995). Students' thoughts during problem-based smallgroup discussions. Instructional Science, 22, 269-278.

Giambra, L. M. (1995). A laboratory method for investigating influences on switching attention to task-unrelated imagery and thought. Consciousness \& Cognition, 4, 1-21.

Grodsky, A., \& Giambra, L. M. (1990/1991). The consistency across vigilance and reading tasks of individual differences in the occurrence of task-unrelated and task-related images and thoughts. Imagination, Cognition \& Personality, 10, 39-52.

HurLburt, R. T. (1979). Random sampling of cognitions and behavior. Journal of Research in Personality, 13, 103-111.

INTEL CORP. (2004). iESP [Computer software]. Retrieved April 2004 from http://seattleweb.intel-research.net/projects/ESM/iESP.html.

Kane, M. J., Brown, L. E., McVay, J. C., Silvia, P. J., MyinGermeys, I., \& KwapIL, T. R. (2007). For whom the mind wanders, and when: An experience-sampling study of working memory and executive control in daily life. Psychological Science, 18, 614-621.

KLINGER, E. (1971). Structure and functions of fantasy. New York: Wiley.

KLINGER, E. (1978/1979). Dimensions of thought and imagery in normal waking states. Journal of Altered States of Consciousness, 4, 97-113.

KLINGER, E. (1999). Thought flow: Properties and mechanisms underlying shifts in content. In J. A. Singer \& P. Salovey (Eds.), At play in the fields of consciousness: Essays in honor of Jerome L. Singer (pp. 2950). Mahwah, NJ: Erlbaum.

KLINGER, E., \& CoX, W. M. (1987/1988). Dimensions of thought flow in everyday life. Imagination, Cognition \& Personality, 7, 105-128.

Mason, M. F., Norton, M. I., Van Horn, J. D., Wegner, D. M., Grafton, S. T., \& Macrae, C. N. (2007). Wandering minds: The default network and stimulus-independent thought. Science, 315, 393 395.

McVay, J. C., \& Kane, M. J. (2009). Conducting the train of thought: Working memory capacity, goal neglect, and mind wandering in an executive-control task. Journal of Experimental Psychology: Learning, Memory, \& Cognition, 35, 196-204.

MoRSELla, E. (2005). The function of phenomenal states: Supramodular interaction theory. Psychological Review, 112, 1000-1021.

Nolen-Hoeksema, S., Wisco, B. E., \& Lyubomirsky, S. (2008). Rethinking rumination. Perspectives on Psychological Science, 3, 400 424.

Raudenbush, S. W., \& BRYK, A. S. (2002). Hierarchical linear models. Applications and data analysis methods (2nd ed.). Newbury Park, CA: Sage.

REASON, J. T. (1990). Human error. Cambridge: Cambridge University Press.

Robertson, I. H., Manly, T., Andrade, J., Baddeley, B. T., \& YIEND, J. (1997). “Oops!”: Performance correlates of everyday attentional failures in traumatic brain injured and normal subjects. Neuropsychologia, 35, 747-758.

Rosenthal, D. M. (2008). Consciousness and its function. Neuropsychologia, 46, 829-840.

Sarason, I. G., Pierce, G. R., \& Sarason, B. R. (1996). Cognitive interference: Theories, methods, and findings. Mahwah, NJ: Erlbaum.

Schoen, J. R. (1970). Use of consciousness sampling to study teaching methods. Journal of Educational Research, 9, 387-390.

SCHOOLER, J. W. (2002). Re-representing consciousness: Dissociations 
between experience and meta-consciousness. Trends in Cognitive Sciences, 6, 339-344.

Schooler, J. W., Reichle, E. D., \& Halpern, D. V. (2004). Zoning out while reading: Evidence for dissociations between experience and metaconsciousness. In D. Levin (Ed.), Thinking and seeing: Visual metacognition in adults and children (pp. 203-226). Cambridge, MA: MIT Press.

Singer, J. L. (1968). The importance of daydreaming. Psychology Today, 1, 18-27.

Singer, J. L., \& Singer, D. G. (2006). Preschoolers' imaginative play as precursor of narrative consciousness. Imagination, Cognition \& Personality, 25, 97-117.

Smallwood, J. M., Baracaia, S. F., Lowe, M., \& Obonsawin, M. (2003). Task unrelated thought whilst encoding information. Consciousness \& Cognition, 12, 452-484.

Smallwood, J., Beach, E., Schooler, J. W., \& Handy, T. C. (2008). Going AWOL in the brain: Mind wandering reduces cortical analysis of external events. Journal of Cognitive Neuroscience, 20, 458-469.

Smallwood, J., Davies, J. B., Heim, D., Finnigan, F., Sudberry, M., O'Connor, R., \& ObonsaWin, M. (2004). Subjective experience and the attentional lapse: Task engagement and disengagement during sustained attention. Consciousness \& Cognition, 13, 657-690.

Smallwood, J., Fishman, D. J., \& Schooler, J. W. (2007). Counting the cost of an absent mind: Mind wandering as an underrecognized influence on educational performance. Psychonomic Bulletin \& Review, 14, 230-236.

Smallwood, J., Fitzgerald, A., Miles, L. K., \& Phillips, L. H. (2009). Shifting moods, wandering minds: Negative moods lead the mind to wander. Emotion, 9, 271-276.

Smallwood, J., McSpadden, M., \& Schooler, J. W. (2007). The lights are on but no one's home: Meta-awareness and the decoupling of attention when the mind wanders. Psychonomic Bulletin \& Review, 14, $527-533$

Smallwood, J., McSpadden, M., \& Schooler, J. W. (2008). When attention matters: The curious incident of the wandering mind. Memory \& Cognition, 36, 1144-1150.

Smallwood, J., O'Connor, R. C., Sudbery, M. V., \& Obonsawin, M. (2007). Mind-wandering and dysphoria. Cognition \& Emotion, 21, 816-842.
Smallwood, J., Riby, L., Heim, D., \& Davies, J. B. (2006). Encoding during the attentional lapse: Accuracy of encoding during the semantic sustained attention to response task. Consciousness \& Cognition, 15, 218-231.

Smallwood, J., \& Schooler, J. W. (2006). The restless mind. Psychological Bulletin, 132, 946-958.

Teasdale, J. D., Proctor, L., Lloyd, C. A., \& Baddeley, A. D. (1993). Working memory and stimulus-independent thought: Effects of memory load and presentation rate. European Journal of Cognitive Psychology, 5, 417-433.

WATKIns, E. R. (2008). Constructive and unconstructive repetitive thought. Psychological Bulletin, 134, 163-206.

WEGNER, D. M. (2002). The illusion of conscious will. Cambridge, MA: MIT Press.

Wiegmann, D. A., Shappell, S. A., Boquet, A., Detwiler, C., HolCOMB, K., \& FAABORG, T. (2005). Human error and general aviation accidents: A comprehensive, fine-grained analysis using HFACS (Final Tech. Rep.). Washington, DC: Federal Aviation Administration.

\section{NOTES}

1. McVay and Kane (2009) also collected working memory capacity (WMC) data from these subjects, but the present sample was too small to detect WMC effects on daily-life mind wandering (it was only about half that of Kane et al., 2007).

2. The significant effects on mind wandering in the present study for the "effort" posed by current activities may have differed here from Kane et al. (2007) because we modified this prompt between studies. In the present study, the prompt asked whether one's activity was mentally effortful, whereas Kane et al. did not use the "mentally" qualifier (thus conflating physical and mental effort).

3. We recognize the possibility that, although mind wandering is often detrimental to immediate task performance, it may serve the adaptive function of allowing people to keep their broader life goals mentally accessible (e.g., Klinger, 1971; Singer, 1968; Singer \& Singer, 2006).

(Manuscript received January 29, 2009; revision accepted for publication June 5, 2009.) 